\title{
Using Fama-French Five-factors Model to Analyze the Impact of COVID-19 on U.S. Medical and Health Industries
}

\author{
Chuyan Wang ${ }^{1, \dagger}$ Zichun $\mathrm{Wu}^{2, \dagger}$ Yi Yang ${ }^{3, *, \dagger}$ \\ ${ }^{1}$ Business School, Rutgers University New Brunswick, Piscataway 08854, America \\ ${ }^{2}$ School of Finance, Hebei University of Economics and Business, Hebei 050062, China \\ ${ }^{3}$ Faculty of Business, University of Nottingham Ningbo China, Ningbo 315000, China \\ ${ }^{*}$ Corresponding author. Email: biyyy14@nottingham.edu.cn \\ These authors contributed equally.
}

\begin{abstract}
Asset pricing theory is one of the most important topics in financial economics. It attempts to explain the asset price or value paid in the future under uncertain conditions. This paper aims to analyze the pharmaceutical market before and after the outbreak of the covid-19 epidemic and explore its possible causes. Then, it studied the coefficients and significance of the two periods before and after the epidemic in detail. And then, these values are analyzed and discussed, and some possible reasons for the differences are given. To be specific, it is studied by using multiple linear regression to analyze the Fama-French five factor model in the health-related industry, which shows the results that the performance of in the health area is more affected by the pandemic, while medical equipment area and drug area are less affected during the covid-19. Overall, the study suggests the 5-factor model shows the outbreak of covid-19 did not benefit the health-related industry. The pharmaceutical industry's demand itself is based on rigid demand, and the medical consumption corresponds to the real clinical demand. The growth core of the medical industry is still technological progress based on the upgrading of patient demand. Therefore, if the pharmaceutical market wants to get long-term development opportunities, the most important thing is to polish products, grasp the development trend of the industry, use the Internet to improve marketing skills and services and pay attention to the cultivation of employees' professional skills.
\end{abstract}

Keywords: Fama-French Model, Covid-19, health, U.S. stock market.

\section{INTRODUCTION}

\subsection{Background}

Beginning at the end of 2019, the COVID-19 burst out. COVID-19 is putting the global economy on the test. Due to the acceleration of globalization, international population mobility has increased, and the incubation period of infectious diseases is greater than the time of international population mobility. This increases the risk of large-scale spread of the virus, and the risks faced by individuals are more complex and diverse up. This makes it impossible for any country to stay out of the epidemic. As the largest, most mature, and most liquid market, the US capital market has also been severely hit. The most intuitive shock is that the
Dow Jones Index set a record decline of 2977 on March 16, 2020, for its worst day in history [1]. As COVID-19 continues to spread in the United States, its impact on the American health system is unprecedented. The American Hospital Association estimates that the revenue of the healthcare system and American hospitals will cost US\$202.6 billion in financial losses, which on average will generate a loss of US\$50.7 billion per month [2], which is undoubtedly a huge impact on the medical industry and capital market in America. However, the positive impact is that COVID19 has exposed the country's negligence in medical care. For example, medical supplies such as personal protective equipment (PPE) for medical staff, hospital equipment, disinfection supplies, toilet paper, and water are in short supply under the sudden outbreak of the 
epidemic. It can prompt American healthcare organizations to formulate a more complete epidemic prevention plan [2]. The pandemic has increased the uncertainty of the capital market, which has also increased the risk of the capital market, which refers to the difference between the future trend of asset prices and people's expectations. To reduce the loss of people's assets at risk, the right asset valuation is necessary. This involves several capital asset pricing models, CAPM, Fama-French three factor model, and Fama-French five factor model, which mainly study the relationship between the expected rate of return of assets in the securities market and risky assets Relationship.

\subsection{Related research}

Before we get down to business, let's take a look at the related research summary. Some scholars have looked at the Fama-French five factors model itself and compared it with other asset pricing models. For example, Chiah et al. aimed to evaluate and then compare Fama-French five-factor and asset, pricing models. With the use of the samples of ordinary stocks traded on ASX from January 1982 to December 2013, they examined the two new factors, profitability, and investment, and therefore found the two factors are significant to improve the explanatory power of the three-factor model. in addition, the five-factor model is capable of explaining the anomalies other models 1 . three factor model, 2. Carhart four-factor model, 3. the US Carhart four-factor model. However, it is found FF model still does not fully explain the time-series variation in portfolio returns. The study suggested a better asset pricing model and provided a comparison of the Australian market with the US market [3]. Besides, Soumaré had done research similarly. Soumaré et al. researched used empirical estimations to compare two asset-pricing models - the Fama-French three-factor pricing model and the Capital Asset Pricing Model (CAPM) - which is better to explain the stock returns on the Bourse Regionale des Valeurs Mobilieres (BRVM). Although the Fama-French model cannot explain the change in the return of more than $60 \%$ of the stocks in the stock market, the three-factor Fama-France model is more suitable than the CAPM model to explain the return changes in BRVM [4]. Lin also had a related thought. Lin provided an empirical evaluation of the Fama-French five-factor model and compared it with the three-factor model through lots of samples from 1997 to 2015 in the Chinese equity market. Lin believes that the five-factor model performs better. However, the Chinese equity market is unique, and Lin found that the three factors, SMB, HML, and RMW, are important for describing average returns in China, with a less important assist from MKT. Lin also finds mixed results in the three-dimensional sorting. The LHS portfolios with extremely low average returns are those that cause serious problems for the five-factor model [5].
These scholars explained the model to us and demonstrated its advantages. In contrast, another group of scholars turned their eyes to applying the model to explain the impact of the epidemic on relevant industries. Zhang is one of them. Zhang et al. tried to seek an appropriate method to forecast how the recovery of tourism is after the impact of COVID-19. As Zhang mentioned, it pays attention to tourism demand when a crisis occurs. These uncertain crises make it unapplicable to use the traditional approach. The team used a Scenario-based Delphi adjustment approach. They first used econometric modeling, then made the baseline forecasts, finally made some judgmental adjustments. It is found that in the source market of China, domestic tourism (Macau, mainland China, Taiwan) would recover first, then followed by other Asian markets. At the same time, long-haul markets like the UK, US may still restrict travel for the period. They predicted the loss of tourism would decline from USD3670 million in 2021 to 1548 million in 2024. Therefore, they suggest that the paper could be a foundation for future tourism demand studies when treating pandemics [6]. The decline in the number of tourists affects related industries, such as the retail industry, which Hou studied. Hou adopted the FamaFrench five-factor model, which five-factor could be calculated through the regression towards selected data to analyze the impact of the Covid-19 on the retail sector. Hou believes that the Covid-19 has reduced the stream of visitors, which seriously affected the retail industry. However, Hou confirmed that most small-size companies perform better than big ones, and the HML becomes a significant factor. He also advised investing in companies with small size and high book-to-market ratios. Besides, focusing on the companies adopting advanced technology is necessary [7].

There is no doubt that COVID-19 has a serious impact on the economy. Fernandes analyzed the impact of the epidemic on the world economy from a macro perspective. Fernandes claimed due to the impact of COVID-19, the global economy will experience a recession. Then, many aspects are studied in Fernandes's article. Because of COVID-19, residents' consumption has decreased; the operation of global supply chains and global trade has been destroyed; a great number of people experienced unemployment; more companies went bankrupt during the period of coronavirus outbreak. However, actual mortality and infection rates are not much related to the economic recession. He gave the conclusion, on average, each additional month's crisis cost is equivalent to $2.5-3 \%$ of global GDP [8]. Ozkan looks at the impact from a micro perspective, the Turkish stock market. Ozkan used multiple regression analysis is carried out by using time series data from July 2009 to June 2015 to test the validity of the Fama and French five factor model in Istanbul Stock Exchange (ISE) and to determine 
whether the value factor is redundant in the model. Ozkan found that the model is viable in ISE between July 2009 and June 2015, although the factor returns are lower compared to Fama and French findings. It is further found that the value factor is not redundant in the Fama-French five factor model [9].

Of course, some scholars also understood directly related to the pharmaceutical industry, which we will discuss today. Macinko et al. researched the effect on healthcare, specifically the cancellation of surgeries or other previously planned procedures in Brazil, the second-largest country influenced by the pandemic. The study used a telephone interview style known as the Brazilian Longitudinal Study of Aging (ELSI-Brazil), over a large number of samples. Despite being faced with limitations of self-reported data, the patterns still showed to indicate the requirement for more control. It is predicted that the health system would collapse without control measures due to the increase in rates of infection and mortality [10]. What's more, the drug is also affected. During estimating the average pretax cost of bringing new molecular entities (NME) to market, DiMasi found that the cost of $\$ 399$ million (almost half) is the cost of capital (COC) for clinical development expenses. Until using the Fama-French three-factor model, it is found that the former estimate of drug development was underestimated because it used the capital asset pricing model (CAPM) before, which is a single factor risk model that is not accurate enough. However, there is no way to calculate the scale and number of drugs that may be influenced by the error [11].

\subsection{Objective}

In this paper, the medical industry is chosen as the research subject, which development is closely related to the pandemic and capital market. Therefore, this research will focus on industry-specific analysis related to this field.

\section{METHOD}

Before CAPM was proposed, there was no clear understanding of how risk affected a firm's cost of capital, and thus its expected rate of return. It was not until 1964 that Sharpe et al. [12] proposed the classic CAPM model, which clearly described the relationship between risk and expected rate of return for the first time using quantitative methods. CAPM introduces the concept of beta value, which is used to measure the sensitivity of asset return to market risk. It points out that the expected return rate of an asset is determined by the expected return rate of the market portfolio and the exposure of the asset to the market risk, and the market portfolio is also called the market factor. According to
CAPM theory, the expected excess return of assets is determined by a linear unitary model:

$$
\mathrm{E}[\mathrm{Ri}]-\mathrm{R}_{\mathrm{F}}=\beta_{\mathrm{i}} \mathrm{E}\left[\mathrm{R}_{\mathrm{M}}-\mathrm{R}_{\mathrm{F}}\right]
$$

However, with the deepening of research, It was found that a single market factor could not well explain the cross-sectional differences of different stock returns at the same time. There is substantial empirical literature confirming that the cross-section of average stock returns is associated with firm size and the book-tomarket ratio (B/M) [13-14], Fama and French [15] proposed a three-factor pricing model by adding SMB and HML based on a market factor in CAPM model. But the three-factor model is unable to effectively measure the profitability of enterprises, and it is found that investors often underestimate the capital investment of enterprises, which leads to the lower stock return rate of enterprises with high investment.

In 2015, Fama and French published a new fivefactor model in which they included profitability and investment factors, and get the new equation:

$\mathrm{R}_{\mathrm{it}}-\mathrm{R}_{\mathrm{Ft}}=\mathrm{a}_{\mathrm{i}}+\mathrm{b}_{\mathrm{i}}\left(\mathrm{R}_{\mathrm{MT}}-\right.$

$\left.\mathrm{R}_{\mathrm{Ft}}\right)+\mathrm{s}_{\mathrm{i}} \mathrm{SMB}_{\mathrm{t}}+\mathrm{h}_{\mathrm{i}} \mathrm{HML}_{\mathrm{t}}+\mathrm{r}_{\mathrm{i}} \mathrm{RMW}_{\mathrm{t}}+\mathrm{c}_{\mathrm{i}} \mathrm{CMA}_{\mathrm{t}}+\mathrm{e}_{\mathrm{it}}$

$\mathrm{Rf}$ means risk-free return rate; $\mathrm{Rm}$ means market return rate; Ri means return rate of asset $i ; E(R m)-R f$ is market risk premium; $\mathrm{SMB}$ is the simulated portfolio return rate of size factor; HML is the simulated portfolio return rate of book-to-market factor.

\section{RESULTS}

The data used in the study comes from industry portfolios compiled by Kenneth R. French, consisting of NYSE, AMEX, and NASDAQ stocks from the period of 2019.05.01-2020.02.28 and 2020.03.01-2020.12.31. This study used the portfolios of the health industry, medical equipment industry, and drugs industry. For each industry, Fama-French five-factor model is adopted to compare the two periods to examine whether the industry was influenced. The results are generated through the multiple linear regression method. As the sample size is large enough, we compare the $t$ statistics of each factor with $\mathrm{t}=1.96$ to test if the factors' significance is under a two-tailed 5\% significance level.

Table 1. 5 factors regression of health

\begin{tabular}{ccccc}
\hline \multirow{2}{*}{ Factor } & \multicolumn{2}{c}{ Before } & \multicolumn{2}{c}{ After } \\
\cline { 2 - 5 } & Coefficients & t Stat & Coefficients & t Stat \\
\hline Intercept & 0.096 & 1.936 & 0.136 & 1.046 \\
Mkt-RF & 0.855 & 14.473 & 1.183 & 19.646 \\
SMB & 0.901 & 8.106 & 0.831 & 5.359 \\
HML & -0.081 & -0.713 & 0.060 & 0.471 \\
RMW & -0.483 & -2.598 & -0.336 & -1.299 \\
CMA & 0.298 & 1.358 & -0.261 & -0.789 \\
\hline
\end{tabular}


Table 2. 5 factors regression of medical equipment

\begin{tabular}{ccccc}
\hline \multirow{2}{*}{ Factor } & \multicolumn{2}{c}{ Before } & \multicolumn{2}{c}{ After } \\
\cline { 2 - 5 } & Coefficients & t Stat & Coefficients & t Stat \\
\hline Intercept & 0.010 & 0.258 & -0.001 & -0.015 \\
Mkt-RF & 0.961 & 20.493 & 0.939 & 29.919 \\
SMB & 0.089 & 1.009 & 0.073 & 0.906 \\
HML & -0.392 & -4.351 & 0.075 & 1.144 \\
RMW & -0.501 & -3.389 & -0.438 & -3.262 \\
CMA & 0.570 & 3.278 & -0.007 & -0.040 \\
\hline
\end{tabular}

Table 3. 5 factors regression of drugs

\begin{tabular}{ccccc}
\hline \multirow{2}{*}{ Factor } & \multicolumn{2}{c}{ Before } & \multicolumn{2}{c}{ After } \\
\cline { 2 - 5 } & Coefficients & t Stat & Coefficients & t Stat \\
\hline Intercept & 0.053 & 1.161 & 0.071 & 1.148 \\
Mkt-RF & 0.965 & 17.742 & 0.928 & 32.111 \\
SMB & 1.387 & 13.623 & 0.967 & 13.021 \\
HML & -0.434 & -4.158 & -0.375 & -6.205 \\
RMW & -0.758 & -4.421 & -1.227 & -9.915 \\
CMA & 0.170 & 0.845 & 0.088 & 0.555 \\
\hline
\end{tabular}

The three industries chose above are all healthrelated industries. As shown in Table 1, it can observe that RMW of health became insignificant, as the t-value changed from -2.598 to -1.299 . Therefore, RMW became redundant in the period of 2020.03.012020.12.31, showing profitability may be less important for the health industry. In Table 2 , the medical equipment also altered significance in HML and CMA. These two factors changed from -4.315 to 1.144 and from 3.278 to -0.040 , respectively, indicating the two factors became insignificant in the period of 2020.03.01-2020.12.31, excessive income is not expected. Investors' risk preference would less influence the industry. No significance has changed in Table 3, which indicates the epidemic may less influence the drugs.

\section{DISCUSSION}

To evaluate the influence of the pandemic outbreak, the study specifically checks the coefficients and the significance over the two periods before and after. Then the analysis compares the values and tries to investigate some plausible reasons for the difference.

\subsection{Health}

It could be observed that the coefficient $\beta M k t-R F$ is 0.855 before the outbreak, which is less than 1 . But it significantly increased to 1.183 while the coefficients are both valid in the two periods. This increase indicates the health industry has become more sensitive to the market, which means the health industry may suffer more than the market in the economic downturn brought by COVID-19. One possible reason is that while the hospitals are busy treating patients infected by COVID19, others who do not have the symptoms of COVID-19 would fear infection and tend to cancel their scheduled surgery or other medical care. The result is consistent with the finding by Macinko [10], who found out in Brazil, more than $17.2 \%$ of people who have chronic conditions canceled their routine medical care or scheduled surgery. The statistics also showed a $48 \%$ decrease in patient hospitalization in critical conditions such as acute myocardial infarction in a health care system in Northern California, United States, between 2020.01.01 to 2020.04.14.

The significance of $\beta \mathrm{SMB}$ did not alter in the periods, while the coefficient changed from 0.901 to 0.831, suggesting that small-cap stocks still receive excessive returns than large-cap stocks. However, it reflects that the expectation of small-cap stocks is slightly lower than before. The HML factor and the CMA factor remain insignificant, indicating that bookto-market value and investors' risk preference were still not explanatory to the industry's measurement. The RMW factor was significant in the first period, but in the second period was no longer significant, indicating profitability lost importance in stock prices. This alteration may be due to the overall economic downturn. Industries with high market sensitivity may show a loss in profitability. Therefore investors would focus on other factors when investing in such industries.

\subsection{Medical equipment}

As shown in Table 2, the results of medical equipment reveal that the coefficient $\beta M K T-R F$ of both two time periods were less than 1 but close to 1 , which reflects the medical equipment industry is approximately the same sensitivity to the market in both periods of 2019.05.01-2020.02.28 and the time period of 2020.03.01-2020.12.31. It can observe that the HML of medical equipment became insignificant, as the tvalue changed from -4.351 to 1.144 , which means that the excessive income is not expected, and also the CMA became insignificant, which means that the investors' risk preference has less of an impact in the period of 2020.03.01-2020.12.31, right after the outbreak of the COVID-19. As can be seen from the change in HML, before the epidemic, the returns of growth stock were greater than value stock, and the net price ratio of growth stock was higher than that of large companies.

However, with the spread and impact of COVID-19, the number of patients is on the rise, some growth companies are limited by production, the capital chain is cut off, and they are acquired, and there is a shortage of medical devices. As a result, some of the medical devices produced by some companies are in the direction of device shortage, so they can seize the opportunity to expand their capacity and scale. Due to the particularity of medical devices, the medical device industry requires strong scientific research, design, and manufacturing capacity due to the particularity of medical devices and high technical barriers. Hence, most enterprises with the ability to produce medical devices are high-value enterprises, so when the epidemic comes, some growth enterprises are not so 
good. At the same time, under the impact of the epidemic, all industries have been severely affected. However, the upgrade of the medical device industry to industry in urgent need has relatively little impact. Therefore, investors will turn their attention to this industry, which reduces the influence preference of investors.

\subsection{Drug}

As shown in Table 3, 4 coefficients of the drug industry are quite significant, which are for the market risk premium, size effect, value effect, and profitability effect, respectively. Still, only two of the coefficients, SMB and RMW, are changing in the pandemic period, which could be seen as some minor change. It indicates that the coefficient $\beta M K T-R F$ of both two time periods was less than 1 but close to 1 , which reflects the drug industry is approximately the same sensitivity to the market in both time periods. Comparing before and after the global pandemic, the $t$ values of SMB are significant, their coefficient are greater than 0 , and the coefficient of HML are smaller than 0 . This shows that the stock returns of small-cap companies are greater than those of large-cap companies, and the stock return of companies with low book-to-market value ratios is higher than the stock return of companies with high book-to-market value ratios. Therefore, small-cap stocks can get higher returns for risk compensation. However, after the global pandemic, the coefficient value of SMB has declined, which may be due to the developing limitation of most small market capitalization companies during the epidemic. In addition, the coefficient of RMW coefficient is going even more negative. That is another change worth mentioning. The possible reason is that the profitability of the drug companies in the COVID-19 period is not so focused on the market since the coefficient is going even more negative, which makes some sense because companies are putting more money into research. Overall, it can be analyzed the performance of drug area during COVID-19 had the sightly change. Although the demand for vaccines surged in the period of the pandemic, the drug industry is a way broader industry than just vaccine producers and researchers. For example, when mentioning those companies that did a good job in the COVID-19 pandemic, we see Moderna, Pfizer, BioNTech, JNJ, and even AstraZeneca or Gilead, etc.. Still, they only form a tiny portion of medical companies or biotech companies. According to the data from NASDAQ, the surging of vaccine demand is reflected in the stock price of Moderna, BioNTech. However, if measured in terms of the industry average, it is pretty doubtable that how much huge impact it might bring.

\section{CONCLUSION}

In conclusion, this article analyzes the influence of COVID-19 on the stock price of medical-related industries with the Fama-French 5-factor model. As shown in the previous part, the health industry suffered the most from the pandemic while the other two medical equipment and drugs industries were less influenced. Although these three industries are similar and highly related, they were influenced by the pandemic at different degrees. This study is important in evaluating the changes of three industries and could also be the basis of recovery analysis in the future. This article could help investors make decisions in medical-related industries as the epidemic still exists.

\section{REFERENCES}

[1] Fernandes, N. (2020). Economic Effects of Coronavirus Outbreak (COVID-19) on the World Economy. Social Science Research Network.

[2] Kaye, A. D., Okeagu, C. N., Pham, A. D., Silva, R. A., Hurley, J. J., Arron, B. L., ... Gamble, J. W. (2020). Economic impact of COVID-19 pandemic on healthcare facilities and systems: International perspectives. Best Practice \& Research Clinical Anaesthesiology.

[3] Chiah, M., Chai, D., Zhong, A., \& Li, S. (2016). A Better Model? An Empirical Investigation of the Fama-French Five-factor Model in Australia. International Review of Finance, 16(4), 595-638.

[4] Soumaré, I., Aménounvé, E. K., Diop, O., Méité, D., \& N'sougan, Y. D. (2013). Applying the CAPM and the Fama-French models to the BRVM stock market. Applied Financial Economics, 23(4), 275-285.

[5] Qi Lin, School of Finance Zhejiang University of Finance \& Economics and Lingnan College, Sun Yat-Sen University. Tel: +86 5718755 7108. Email: qlin_sf@zufe.edu.cn.

[6] Zhang, H., Song, H., Wen, L., \& Liu, C. (2021). Forecasting tourism recovery amid COVID-19. Annals of Tourism Research, 87, 103149.

[7] Kaiyan Hou, School of Accounting and Finance, The Hong Kong Polytechnic University, Hong Kong, China kai-yan.hou@connect.polyu.hk, 2021 4th International Conference on Global Economy, Finance and Humanities Research (GEFHR 2021)

[8] Fernandes, N. (2020). Economic Effects of Coronavirus Outbreak (COVID-19) on the World Economy. Social Science Research Network. 
[9] Nesrin Ozkan, Bursa Uludağ University, Social Sciences Faculty, Business Administration, Bursa, Turkey.

[10] Macinko, J., Woolley, N., Seixas, B., Andrade, F., \& Lima-Costa, M. (2020). Health care seeking due to COVID-19 related symptoms and health care cancellations among older Brazilian adults: The ELSI-COVID-19 initiative. Cadernos De Saúde Pública, 36Suppl 3(Suppl 3), E00181920.

[11] Vernon, J. A., Golec, J. H., \& Dimasi, J. A. (2009). Drug development costs when financial risk is measured using the Fama-French three-factor model. Health Economics, 19(8), 1002-1005.

[12] Sharpe, William F. 1964. "Capital Asset Prices: A Theory of Market Equilibrium under Condi- tions of Risk." Journal of Finance. 19:3, pp. 425- 42.

[13] Banz, Rolf W. 1981. "The Relationship Be- tween Return and Market Value of Common Stocks." Journal of Financial Economics. 9:1, pp. 3-18.

[14] Fama, Eugene F. and Kenneth R. French. 1992. "The Cross-Section of Expected Stock Re- turns." Journal of Finance. 47:2, pp. 427-65.

[15] Fama, Eugene F. and Kenneth R. French. 1993. "Common Risk Factors in the Returns on Stocks and Bonds." Journal of Financial Economics. 33:1, pp. 3-56. 